\title{
Screening for Fragile X Syndrome: Parent attitudes and perspectives
}

Debra Skinner, PhD, Karen L. Sparkman, EdS, and Donald B. Bailey, Jr., PhD

\begin{abstract}
Purpose: This study examined the attitudes and beliefs of 442 parents of children with fragile X syndrome (FXS) regarding different screening options for FXS. Methods: A survey was administered to parents of children with FXS across the U.S. Results: Parents indicated their support for voluntary screening for FXS, especially carrier and newborn screening. They also thought advantages of widespread screening to be more likely than disadvantages. Conclusion: Parents' support for FXS screening is at odds with current screening criteria, but as new genetic knowledge and technologies reconfigure these criteria, it will be important to take parents' perspectives into account. Genet Med 2003:5(5):378-384.
\end{abstract}

Key Words: genetic screening, fragile $X$ syndrome, parent attitudes

Research on the human genome has spawned a rapid increase in discoveries of genes associated with specific disorders. Diagnostic technology has kept apace as over 400 genetic tests are available in clinical settings, with hundreds more available for research purposes. ${ }^{1}$ This new genetic knowledge and technology have generated increased consumer interest in and demand for testing, and debates about who should be tested for what and when. ${ }^{2-4}$ Discussions are now underway regarding the economic, social, and ethical benefits and risks of various genetic tests, and which ones should come under the auspices of public health and state newborn screening programs. ${ }^{1,5,6}$

Criteria used to determine which disorders are appropriate targets for screening have traditionally included the relative prevalence of the disorder, the availability of an accurate and cost-effective screening procedure, and evidence that screening results in a direct medical benefit to the identified individual. But as tests for more disorders become available, there have been calls from a number of fronts for an expansion of these criteria. Other criteria promoted for consideration include the need for voluntary participation, adequate follow-up and informational systems, and adequate protection against possible social or psychological harm. ${ }^{7}$ A recent task force report argued that knowledge about genetic risk is "medically necessary information" and this constitutes a sufficient rationale for screening even if direct medical benefit has not been proven. ${ }^{8}$

In these debates, relatively little attention has been paid to the desires of parents and other consumers who might be directly affected by screening programs. Significant participation by consumers on state screening advisory committees is not

From the FPG Child Development Institute, University of North Carolina at Chapel Hill. Debra Skinner, PhD, FPG Child Development Institute, CB \#8180, University of North Carolina at Chapel Hill, CB \#8180, 105 Smith Level Rd, Chapel Hill, NC 27599-8180.

Received: April 22, 2003.

Accepted: May 14, 2003.

DOI: 10.1097/01.GIM.0000086480.69309.1E standard practice, ${ }^{9}$ despite the fact that consumers have a fundamental stake in the consequences of screening programs. And although current criteria are generally construed to be protective of consumers and prevent them from being subjected to unwanted screening and unforeseen consequences of it, some research suggests that parents are more supportive of screening than is generally perceived by clinicians or policy makers. ${ }^{10}$

Fragile $\mathrm{X}$ syndrome (FXS), the most common inherited form of mental retardation, exemplifies many of the issues raised in these debates. FXS is a single-gene disorder caused by a trinucleotide repeat expansion (CGG) at Xq27.3 near the promoter region on the upper end of the FMR1 gene. ${ }^{11}$ The range of CGG repeats for someone in the general population is approximately 6 to 54 . Women who are premutation carriers have 55 to 200 repeats, are at risk for having a child with the disorder, but typically are themselves unaffected. (Note: Expansion to the full mutation typically only occurs through female transmission. Males with the premutation are not shown to be at risk of having affected children, but their daughters are.) Individuals with 200 or more CGG repeats have a full mutation, usually resulting in methylation of the FMR1 gene that leads to "silencing" of the gene and loss of production of the fragile X mental retardation protein (FMRP). The full mutation is associated with features of FXS in males, whereas females have a more variable phenotype.

FXS results in significant impairments in development and adaptive function. ${ }^{12,13}$ Males with the full mutation usually exhibit moderate to severe intellectual impairment, a range of language disorders, and social and behavioral difficulties, including problems with attention, impulsivity, anxiety, and arousal. ${ }^{14}$ As many as $25 \%$ to $35 \%$ also meet the diagnostic criteria for autism. ${ }^{15,16}$ Females are usually less severely affected and tend to score in the mild-to-average range of intellectual function and display milder but characteristic patterns of social anxiety and challenges in executive function. ${ }^{17}$ 
Estimates of prevalence vary, but a recent review suggests that the number of Caucasian males with the full mutation is approximately $1 / 4000$. Prevalence estimates for the premutation or carrier form of the disorder in Caucasian females range from $1 / 246$ to $1 / 468$, and for Caucasian males, the prevalence of the premutation is approximately $1 / 1000 .{ }^{18}$

Unlike Down syndrome or spina bifida, the defining features of FXS are not so distinctive as to allow identification at birth. Most parents believe that they have given birth to a normal child, and it is only when developmental delays become obvious that parents or physicians become concerned. Research in the U.S. and the United Kingdom demonstrates that parents usually experience a long process of discovering their child's disorder, and often it is not diagnosed until age 3 or older. ${ }^{19,20}$ A recent survey of several hundred parents found numerous negative consequences associated with a later diagnosis. Parents had to "convince" professionals that something was wrong with their child and had to find someone who was knowledgeable enough about FXS to request a DNA test. Their children often missed two or more years of possible early intervention services that would have been available had they been identified earlier. And many families had other children before the diagnosis of FXS in their first child, and as a result, some had two or more children with the disorder. ${ }^{21}$

Given the prevalence rates of FXS and the availability of accurate and diagnostic genetic testing that could be used to detect an abnormal fragile $\mathrm{X}$ gene before conception, prenatally, or in newborns, discussions have begun weighing the costs and benefits of various options for screening. ${ }^{18,22-25}$ Potential benefits of early detection include eliminating parents' frustrations of months or years of searching for the reason for the child's delays or behavioral problems, providing immediate access to early intervention services and information about FXS, and providing information relevant to the reproductive decisions of parents and extended family members. ${ }^{19,22,26}$ Concerns about testing for this and other genetic disorders include the potential that a positive result would cause parents emotional anguish, affect bonding with the child, lead to discrimination and loss of privacy, violate the child's autonomy to choose whether or not to be tested as an adult, be cost prohibitive for widespread use, and increase abortions. ${ }^{22,26-29}$

Newborn screening may be the most likely option in the near future for FXS screening, but currently FXS does not meet all the state newborn screening criteria as established by a series of consensus reports over the past decade. ${ }^{30,31}$ In particular, because there is currently no cure or validated medical treatment, FXS does not meet a strict interpretation of the screening criterion of providing a direct medical benefit for the child, despite the fact that all identified children would immediately be eligible for services under the Individuals with Disabilities Education Act. However, the context in which newborn screening criteria were established is changing dramatically as new genetic knowledge and technologies reconfigure public and policy perspectives. ${ }^{32-36}$

FXS is likely to be a prime candidate for inclusion in expanded newborn screening programs and could be a test case for the inclusion of other disorders for which no medical cure or treatment exists. Much discussion of task forces and state advisory boards will focus on the advantages and disadvantages of FXS screening from medical, economic, and ethical perspectives, but it is important that consumers' perspectives on these and other dimensions be included as well. Recent recommendations by task forces and advocacy groups call for more consumer representation on state advisory boards and committees to insure that those who have used genetic testing and know firsthand the impact of genetic disorder on family life have a voice in determining whether or not new genetic tests and screening policies should be adopted. ${ }^{4,9,31}$

In addition to consumer representation on advisory boards, more U.S. based research is needed on consumers' attitudes and beliefs about different screening programs, especially those who may be immediately affected by likely changes in newborn screening criteria, such as parents of children with FXS. This article addresses this need by surveying a U. S. sample of parents of children with FXS about their attitudes on the best time for screening for FXS and their beliefs about the ramifications of widespread screening. Although they do not represent all consumers, these parents provide important perspectives from a group that has been significantly affected by a disorder not currently tested for in screening programs. It is important that their concerns and desires have a place in ongoing debates and decisions about the inclusion of disorders like FXS in newborn screening programs.

\section{METHODS}

The authors, with input from FXS researchers, parents of children with FXS, and staff from the National Center on Birth Defects and Developmental Disabilities of the Centers for Disease Control, developed and revised the survey used for this study. The survey and recruitment procedures were approved by the academic affairs institutional review board of the University of North Carolina at Chapel Hill. Surveys were mailed to (1) 85 families participating in a longitudinal study of development in children with FXS by the third author, (2) 400 families on the mailing list of the FRAXA Research Foundation, and (3) 50 parents who requested a survey in response to Web site announcements posted by the research project and FRAXA. Two surveys were mailed to each family, and mothers and fathers were instructed to complete the survey separately. The survey assessed (1) how parents found out about FXS, (2) the impact of the diagnosis, and (3) what they thought about different screening strategies for FXS and the issues associated with these strategies. In a companion article, we report data on parents' experiences in discovering FXS in their child. ${ }^{21}$ In this study, we report the findings related to parents' beliefs about the desirability and consequences of more widespread genetic testing for FXS.

Descriptive statistics were used to analyze responses to closed-ended items. Correlational and univariate analyses were then used to determine whether variables related to gender, education, income, and religiosity (i.e., religious affilia- 
tion, frequency of religious activities, and importance of religious faith) predicted parents' responses. A systematic content analysis was conducted on the written explanations parents gave for their choices to the close-ended items. This analysis provided insights into how parents' experiences shaped their attitudes about screening and added contextual information for interpretation of the quantitative results. ${ }^{37,38}$

\section{RESULTS}

\section{Demographic characteristics of the sample}

Excluding surveys from adoptive parents and stepparents, we received 442 usable surveys: 279 (63\%) from biological mothers of an affected child and 163 (37\%) from biological fathers. This represents 152 families for which both the mother and father responded, 127 families for which the mother only replied, and 11 families for which the father only replied. In terms of ethnicity, 416 (94\%) respondents indicated they were "non-Hispanic white/Caucasian." The remainder of the sample included 8 African Americans, 6 Hispanic/Latinos, 3 Asian/ Asian Americans, and 9 parents whose ethnicity was unknown or diverse. Overall, the respondents were well educated, as $34.7 \%$ had taken some graduate classes or earned a graduate degree, $29.2 \%$ had completed college, and $27.7 \%$ had completed technical school or taken some college courses. Only $8.4 \%$ had a high school degree or less. In regards to family household income, $18.3 \%$ of respondents reported a yearly income of less than $\$ 51,000,40 \%$ had an income between $\$ 51,000$ and $\$ 100,000$, and $40.5 \%$ had an income over $\$ 100,000$ a year. Almost one-third (31.2\%) of the sample reported being Catholic. The remainder who had some religious affiliation were Protestants (38.5\%), Jewish (13.1\%) or Other (6.3\%). A majority (57.8\%) reported that religious faith was important or extremely important to them and their family in daily life, $20.9 \%$ indicated religious faith was somewhat important, and $21.3 \%$ responded that faith was only a little or not important.

\section{Timing for genetic testing}

Parents were asked to indicate, on a 5-point Likert scale ranging from "strongly disagree" to "strongly agree," their opinion as to whether voluntary genetic testing for FXS should be offered to identify: (1) women as carriers of FXS before becoming pregnant; (2) women as carriers during pregnancy; (3) babies before birth; (4) newborns; or (5) children who experience developmental or behavioral problems. Parent responses are summarized in Table 1. Overwhelmingly, respondents agreed or strongly agreed that genetic testing for FXS should be offered to women before conception (93\%), for newborns $(82.6 \%)$, or when behavioral or developmental problems are noticed in the child (95.9\%). Responses showed more variability and uncertainty for carrier screening during pregnancy and prenatal testing of the fetus, but even so, about two-thirds of the sample agreed or strongly agreed that voluntary testing should be offered at these times. No important or
Table 1

Percentage of parents reporting when voluntary genetic testing should be offered $(n=442)$

\begin{tabular}{|c|c|c|c|c|c|}
\hline Time & $\begin{array}{l}\text { Strongly } \\
\text { disagree }\end{array}$ & Disagree & Uncertain & Agree & $\begin{array}{c}\text { Strongly } \\
\text { agree }\end{array}$ \\
\hline Preconception (carrier) & 0.9 & 0.9 & 2.7 & 18.8 & 74.2 \\
\hline Prenatal (carrier) & 4.3 & 6.6 & 13.8 & 20.8 & 50.7 \\
\hline Prenatal (fetus) & 5.9 & 7.2 & 18.8 & 17.7 & 47.3 \\
\hline Newborn & 0.9 & 4 & 8.6 & 19.5 & 63.1 \\
\hline At first concerns & 0.2 & 0.2 & 0.5 & 7.9 & 88 \\
\hline
\end{tabular}

meaningful differences between the responses of mothers and fathers were noted.

Parents were also asked to choose the one best time to offer testing for FXS. Responses to this question and representative comments are summarized in Table 2. The majority of respondents chose "before a woman gets pregnant" $(79.9 \%)$ as the best time to screen for FXS. The two most frequent reasons given in open-ended responses were that testing at this time would inform parents if they were carriers and provide information that would allow for reproductive choice. Some parents stated that learning they were carriers would lead them to explore adoption or the use of reproductive technologies. A few parents wrote that testing at this time would prevent abortion and the birth of children with FXS, presumably because they believed carriers would choose not to have children, and thus decrease the need for special services and care.

Only $3.9 \%$ of parents thought the best time for testing was "during pregnancy." Their reasons were that testing during pregnancy provided choices, prepared parents for the consequences of having a child with FXS, and was more practical than before pregnancy. Parents who chose "immediately after birth" (3.4\%) thought newborn screening would allow early access to services and the information needed to make the best decisions for the child. Others thought testing at this time would prevent abortion, and that this was the most practical timing for screening. The 7\% who chose "when the child is experiencing problems" believed that earlier testing might cause parents undue stress and worry, lead to termination of pregnancies, or cause an inability to accept the affected child. Among this group there was a sense that it was better not to know one's genetic inheritance until problems arise.

\section{Effects on bonding}

Parents were asked if they thought a diagnosis of FXS "during pregnancy" would make bonding more difficult, easier, or have no effect if they had not previously known about the possibility of FXS. Slightly over half (52.9\%) believed that the diagnosis would have no effect on bonding, explaining that the child is their child no matter what and would be loved the same as any other child. Parents who indicated that bonding would be more difficult (11.3\%) explained that the diagnosis might cause parents to worry about how to manage a child with FXS and the additional 
Table 2

Parents' beliefs about best time to offer testing for Fragile X syndrome $(n=442)$

\begin{tabular}{|c|c|c|}
\hline Time & Number $(\%)$ & Representative responses \\
\hline Should not be offered at any time & $5(1.1 \%)$ & No responses given \\
\hline Before a woman gets pregnant & $353(79.9 \%)$ & $\begin{array}{l}\text { "She would know if she is a carrier of Fragile X." } \\
\text { "Would provide information for reproductive choice." }\end{array}$ \\
\hline During pregnancy & $17(3.9 \%)$ & $\begin{array}{l}\text { "To make an informed decision and know the consequences of a child living with FX." } \\
\text { "At the time I was } 37 \text { yrs old with my first child. I was offered \& had testing for Down syndrome. } \\
\text { Why not test for something as prevalent?" }\end{array}$ \\
\hline Immediately after birth & $15(3.4 \%)$ & $\begin{array}{l}\text { "Immediately after birth would benefit everyone, especially the baby. Support could be given } \\
\text { immediately and the parents could learn and make decisions about very best choices." } \\
\text { "Then you could help plan a course of care and education most loving and beneficial to the child } \\
\text { and not have to feel guilty or crazy-you'd know what's wrong." }\end{array}$ \\
\hline $\begin{array}{l}\text { When the child is experiencing } \\
\text { problems }\end{array}$ & $31(7 \%)$ & $\begin{array}{l}\text { "I personally believe you should accept your child as is, rather than seeking information to prevent } \\
\text { a certain type of pregnancy." }\end{array}$ \\
\hline Other/don't know & $15(3.4 \%)$ & $\begin{array}{l}\text { "Should be offered when you get married-not everyone plans a pregnancy." } \\
\text { "Whenever a woman wants it. It should be an individual choice." }\end{array}$ \\
\hline Missing & $6(1.4 \%)$ & \\
\hline
\end{tabular}

demands placed on the family. Some wrote that the diagnosis could engender negative emotions that might affect bonding. Those few (5.4\%) who thought knowing would make bonding easier said that knowing the diagnosis would help them gain a better understanding of the child or cause them to spend more time with the child, thus facilitating bonding. Over a quarter (28.5\%) of the parents were uncertain how bonding would be affected, stating they would most likely experience a range of feelings, both positive and negative, or that they were unable to judge never having experienced this situation.

We also asked if bonding would be affected if they learned their newborn had FXS. The majority $(60.2 \%)$ believed there would be no effect. Others thought it would be easier (9.3\%), more difficult (10\%), or were uncertain (18.6\%) how bonding would be affected. Explanations for these choices did not vary from those given above for identification of FXS during pregnancy.

\section{Carrier testing}

Parents were asked if they would want to be informed, either during pregnancy or after birth, if their child was a carrier of FXS (as opposed to an affected child with the full mutation). Overwhelmingly, parents reported "yes," they would like to be informed of their child's carrier status during pregnancy (86.9\%) and as a newborn baby (94.3\%). Parents' explanations for why they would want to know were very similar for both times. They wanted to know as much as possible about their child so that they could make appropriate decisions and plans; they wanted to know because carriers might have learning problems; by knowing they could better prepare the child to deal with the diagnosis and understand the reproductive risks; and they could educate themselves and others about how FXS might potentially affect their child. Parents also indicated that knowing carrier status was important for their own reproductive future as well as for that of their children and relatives. The few respondents who did not want to know carrier status of the baby during pregnancy (6.3\%) or after birth (1.6\%) indicated that this information would not be relevant at these times and would create unnecessary stress. However, they stated they would want to know carrier status at a later time, especially when they would need to inform the child about reproductive risks.

\section{Perceived outcomes of widespread genetic screening}

Parents were given a 3-point Likert scale with choice options of "not at all likely," "somewhat likely," or "very likely," and asked to rate the extent to which potential outcomes of widespread genetic screening for FXS might occur. The results are displayed in Table 3. For the most part, parents thought screening would result in more positive outcomes than negative outcomes. The most likely positive results would be that an early diagnosis would help them locate information about FXS, obtain services earlier, increase understanding of the child's special needs, inform relatives of their possible carrier status, and make informed reproductive decisions.

Parents indicated that the most likely negative outcomes would be increased worry about the child's future health and development, increased parental stress, and worry about how others might treat them or their children. Insurance discrimination and strained relations with extended family members were thought to be somewhat likely. Most respondents thought it more unlikely that getting the FXS diagnosis would disrupt bonding or that the test would endanger the child's health.

Not all demographic variables had enough variance to test for their effect on parents' responses, but those we did test for (gender, income, and education) showed no significant correlations. In general there was little variability in parent responses across any of the demographic variables. However, frequency of religious activities, importance of faith, and religious affiliation were modestly related to some of the variables 
Table 3

Parents' beliefs about possible outcomes of widespread testing and early diagnosis of Fragile X syndrome $(n=442)$

\begin{tabular}{|c|c|c|c|c|}
\hline Scale item ${ }^{a}$ & Missing & Not likely & $\begin{array}{l}\text { Somewhat } \\
\text { likely }\end{array}$ & Very likely \\
\hline Would disrupt bonding with the child (10) & 1.58 & 66.97 & 29.19 & 2.26 \\
\hline Prenatal testing would endanger the baby's health (1) & 2.71 & 50.00 & 40.72 & 6.56 \\
\hline $\begin{array}{l}\text { Would strain relations with family members because of the need to inform them that } \\
\text { they might be carriers of FXS (13) }\end{array}$ & 0.45 & 32.13 & 54.52 & 12.90 \\
\hline Would result in discrimination by insurance companies ( 8 ) & 3.85 & 22.17 & 57.47 & 16.52 \\
\hline Would increase worries about how others might treat the child or parents (6) & 1.13 & 13.80 & 46.15 & 38.91 \\
\hline $\begin{array}{l}\text { Would increase parents' stress because of decisions they might have to make about } \\
\text { having children (4) }\end{array}$ & 0.68 & 9.73 & 44.12 & 45.48 \\
\hline Would increase parents' worry about the child's future health and development (11) & 0.68 & 6.56 & 37.78 & 54.98 \\
\hline Would help get services not available without a diagnosis (9) & 1.13 & 2.71 & 18.78 & 77.38 \\
\hline Would inform planning for additional children (7) & 0.45 & 1.36 & 14.03 & 84.16 \\
\hline $\begin{array}{l}\text { Would allow parents to inform family members about the possibility they are } \\
\text { carriers (12) }\end{array}$ & 0.45 & 0.90 & 11.09 & 87.56 \\
\hline Would increase parents' and others' understanding of the child's special needs (5) & 0.45 & 0.45 & 10.86 & 88.24 \\
\hline Would help parents obtain services earlier for the child (3) & 0.68 & 0.23 & 5.66 & 93.44 \\
\hline Would help parents gather information to better understand FXS (2) & 0.45 & 0.23 & 5.66 & 93.67 \\
\hline
\end{tabular}

${ }^{a}$ The number at the end of the item indicates the order it appeared on the survey.

of interest. More frequent religious activity was significantly correlated to disagreement with genetic testing for mothers or fetuses during pregnancy $(0.23$ and $0.25, P<0.05$ for mothers; 0.31 and $0.28, P<0.05$ for fathers). Self ratings of the importance of faith were significantly correlated to disagreement with genetic testing during pregnancy among fathers ( 0.30 and $0.29, P<0.05$ ), and Catholic fathers were less likely to strongly agree to genetic testing for women before pregnancy $(\mathrm{F}=5.66$, $P=0.018)$.

\section{DISCUSSION}

This study surveyed a large cohort of parents residing in the U.S. who have children with FXS to examine their perspectives on genetic screening for the disorder and possible ramifications of widespread screening. Overall, parents strongly favored carrier screening for women, and newborn screening for both affected and carrier status. This desire to know newborn carrier status differs from an earlier study with a small number of female carriers of FXS who indicated that the optimal time of carrier testing was 10 years of age. ${ }^{39}$ Results also indicated that parents thought benefits of screening were more likely than risks. Both closed-ended and open-ended responses attested to the desire of the vast majority of parents to know their child's affected or carrier status as soon as possible for future reproductive planning, to better understand the child, and for locating appropriate information and services.

Parents' responses did not vary significantly by gender, income, or education. This conclusion is limited by the fact that this respondent pool was primarily Caucasian and did not ad- equately sample very low-income families. However, an inspection of the small number of individual cases of minority and lower income respondents suggests that their responses are very much concordant with those of the larger sample. It is possible that having a child with FXS creates some commonality of experiences that cross-cuts these groups. This is not to indicate that all parents expressed the same beliefs. There were parents who did not agree with the predominant views, but these differences could not be predicted by ethnicity, education, or income status. Religious factors did decrease some parents' willingness to test for FXS during pregnancy, most likely due to their belief that this would increase abortions.

On the whole, parents in this study were optimistic about the benefits of screening and favored voluntary, widespread use of available screening tools. These perspectives place parents somewhat at odds with more conservative approaches to screening endorsed in human genetics and public health. Current screening principles do not promote testing for carrier status of children, for genetic disorders for which no medical cure or proven intervention exists, or for carrier screening for the purpose of informing reproductive decisions. 2,27,33

Traditional principles of newborn screening are currently being challenged due to the availability of molecular genetic analyses and tandem mass spectrometry (MS/MS) that allow screening for numerous disorders. ${ }^{33-35}$ As these tests become commercialized through private laboratories and publicized through the media, consumer demands increase for expanded state screening programs. Proponents of expanded or supplemental testing argue that early detection provides information and interventions that can improve health and prevent disease, 
and inform decisions about health and reproduction. ${ }^{33,36}$ Consumers invoke parental rights to have access to any information related to their children's health. This desire to know puts parents at center stage of a debate about who has the right to know what and when.

Most bioethicists, feminists, social scientists, and disability rights advocates present less optimistic views about the possible ramifications of genetic testing. ${ }^{40,41}$ For many of these critics, the "new genetics" brings the threat of a "new eugenics" where an expansion of prenatal or newborn screening could lead to the elimination of individuals who carry certain genetic disorders or even propensities for disease or disability. ${ }^{42-46} \mathrm{An}$ other concern is that having knowledge of one's own or others' genetic makeup could lead to genetic determinism. Thus an affected individual's behavior and personality would be seen as the immutable products of biology, eliminating the influence of social and environmental factors in that individual's development. ${ }^{47}$ Other risks include discrimination by insurance companies, workplaces, and other institutions; stigmatization of carriers, affected individuals, and families; and undue worry for parents, among other social and psychological ills. . $^{40,42-44}$ Even if one has a genetic diagnosis, providing risk assessment for individuals with known genetic disorders, even when caused by mutations within a single gene, is rarely straightforward. Risk assessment involves the multiple components of determining the chance that someone has inherited an altered gene, the chance that this alteration will produce a disorder, and the predicted severity of the symptoms. ${ }^{48}$ Some critics argue that knowing about the genetic condition may endanger the parent-child bond or the child's self-concept, thus not knowing may provide a protective barrier for the child and family..$^{49}$ Furthermore, it is argued that genetic disorders are a family affair that affects extended, past, and future kin. Some relatives would rather not be informed of possible conditions. ${ }^{48}$ Feminist critiques of testing note that women bear the primary responsibility of decision-making for testing and for the choices made based on testing results. Numerable researchers have documented how these choices are shaped and constrained by both implicit and explicit messages in genetic counseling, the tests themselves, and medical discourse. ${ }^{50-53}$

These critiques raise important issues that parents may or may not be aware of, or may or may not agree with, but these issues cannot be adequately resolved without the representation and perspectives of families like those in this study who have experienced firsthand the psychological and social ramifications of an inheritable genetic disorder.

One limitation of this study for matters of representation is that respondents were from highly selective groups (i.e., families on a mailing list for a foundation and families participating in a research project). Although there was a range of income and educational levels, a majority of respondents were well educated and higher income, and almost all were Caucasian. Thus, generalizations to all families in the U.S. population may not be warranted. Although parenting a child with fragile $\mathrm{X}$ syndrome may create some common experiences across social groups, there may be diversity in beliefs about genetic test- ing and widespread screening among members of different ethnic and socioeconomic groups that were not captured in this study.

Another limitation is that we did not survey other groups of parents for a comparative study of attitudes toward screening for FXS. We do not know if (potential) parents of typically developing children, or parents of children with other genetic disorders would respond similarly to our survey questions as did parents of children with FXS, but related studies suggest that these groups are largely favorable of screening for many genetic conditions. Polls done with large, national populationbased studies of U.S. adults indicate that about $75 \%$ would take a genetic test to see if they were carriers of potentially fatal diseases before having children and about two-thirds say they would use prenatal testing to detect genetic diseases in fetuses in the early stages of pregnancy. ${ }^{54}$ Reviews of numerous studies done with small nonprobability samples of individuals who are carriers or potential carriers of genetic disorders show some variation in beliefs depending on the specific condition under question, but overall report relatively large proportions of these samples in favor of carrier and prenatal testing for a variety of genetic disorders. ${ }^{54,55}$ Further research is necessary to determine more systematically attitudes toward testing held by individuals with and without different disorders about different disorders, and the influence of religion, ethnicity, and education on attitudes. Through this research and through representation of parents from diverse groups, consumers can gain more of a voice in decision-making bodies and expand public policy debates on genetic screening.

\section{Acknowledgments}

This research was funded in part by Grant No. H324C990042, Office of Special Education Programs, U.S. Department of Education. The authors express their appreciation to the FRAXA Foundation, the National Center for Birth Defects and Developmental Disabilities of the Centers for Disease Control, and the parents who helped with various aspects of this study.

\section{References}

1. Yoon PW, Chen B, Faucett A, Clyne M, Gwinn M, Lubin IM et al. Public health impact of genetic tests at the end of the 20th century. Genet Med 2001;3:405-410.

2. Committee on Bioethics. Ethical issues with genetic testing in pediatrics. Pediatrics 2001;107:1451-1455.

3. McCabe LL, McCabe ER. Postgenomic medicine: presymptomatic testing for prediction and prevention. Clin Perinatol 2001;28:425-434.

4. Newborn Screening Task Force. Serving the family from birth to the medical home. Newborn screening: a blueprint for the future - a call for a national agenda on state newborn screening programs. Pediatrics 2000;106:389-422.

5. Khoury MJ. Genetics Working Group. From genes to public health: the applications of genetic technology in disease prevention. Am J Public Health 1996;86:1717-1722.

6. Hiller EH, Landenburger G, Natowicz MR. Public participation in medical policymaking and the status of the consumer autonomy: the example of newborn-screening programs in the United States. Am J Public Health 1997;87:1280-1288.

7. Henneman L, Poppelaars FAM, ten Kate LP. Evaluation of cystic fibrosis carrier screening programs according to genetic screening criteria. Genet Med 2002;4:241249.

8. Ireys HT, Wehr E, Cooke RE. Defining medical necessity: strategies for promoting access to quality care for persons with developmental disabilities, mental retardation, and other health care needs. Arlington, Virginia: National Center for Education in Maternal and Child Health, 1999 


\section{Skinner et al.}

9. Davidson ME, Weingarten K, Pollin TI, Wilson MA, Wilker N, Hsu N et al. Consumer perspectives on genetic testing: implications for building family-centered public policies. Families, Systems, and Health 2000;18:217-235.

10. Zamerowski ST, Lumley MA, Arreola TA, Dukes K, Sullivan L. Favorable attitudes toward testing for chromosomal abnormalities via analysis of fetal cells in maternal blood. Genet Med 2001;3:301-309.

11. Warren SF, Ashley CT. Triplet repeat expansion mutations: the example of fragile $\mathrm{X}$ syndrome. Annu Rev Neurosc 1995;18:77-99.

12. Bailey DB, Nelson D. The nature and consequences of fragile X syndrome. Ment Retard Dev Disab Res Reviews 1995;1:238-244.

13. Mazzocco MMM. Advances in research on the fragile X syndrome. Ment Retard Dev Disab Res Reviews 2000;6:96-106.

14. Hagerman RJ, Cronister A, editors. Fragile X. syndrome: diagnosis, treatment, and research, 3rd ed. Baltimore: Johns Hopkins University Press, 2002.

15. Bailey DB, Mesibov GB, Hatton DD, Clark RD, Roberts JE, Mayhew L. Autistic behavior in young boys with fragile X syndrome. J Autism Dev Disord 1998;28:499_ 508.

16. Rogers SJ, Hehner EA, Hagerman RJ. The behavioral phenotype in fragile X: symptoms of autism in very young children with fragile $\mathrm{X}$ syndrome, idiopathic autism, and other developmental disorders. J Dev Beh Pediatr 2001;22:409-417.

17. Lachiewicz AM. Females with fragile X syndrome: a review of the effects of an abnormal FMR1 gene. Ment Retard Dev Disab Res Reviews 1995;1:292-297.

18. Crawford DC, Acuña JM, Sherman SL. FMR1 and the fragile X syndrome: human genome epidemiology review. Genet Med 2001;3:359-371.

19. Bailey DB, Skinner D, Hatton D, Roberts J. Family experiences and factors associated with the diagnosis of fragile X syndrome. J Dev Beh Pediatr 2000;21:315-321.

20. Carmichael B, Pembrey M, Turner G, Barnicoat A. Diagnosis of fragile X syndrome: the experiences of parents. J Int Disab Res 1999;43:47-53.

21. Bailey DB, Skinner D, Sparkman KA. Discovering fragile X syndrome: family experiences and perceptions. Pediatrics 2003;111:407-416.

22. Bailey DB, Roberts JE, Mirrett P, Hatton DD. Identifying infants and toddlers with fragile X syndrome: issues and recommendations. Inf Young Child 2001;14: 24-33.

23. Pembrey ME, Barnicoat AJ, Carmichael B, Bobrow M, Turner G. An assessment of screening strategies for fragile X syndrome in the UK. Health Tech Assess 2001; 5:1-95.

24. Murray J, Cuckle H. Cystic fibrosis and fragile X syndrome: the arguments for antenatal screening. Comb Chem High Throughput Screen 2001;4:265-272.

25. Pesso R, Berkenstadt M, Cuckle H, Gak E, Peleg L, Frydman M et al. Screening for fragile X syndrome in women of reproductive age. Prenat Diagn 2000;20: 611-614.

26. Roy JC, Johnsen J, Breese K, Hagerman R. Fragile X. syndrome: what is the impact of diagnosis on families. Dev Brain Dysfunct 1995;8:327-335.

27. Asch DA, Hershey JC, Pauly MV, Patton JP, Jedrziewski MK, Mennutti MT. Genetic screening for reproductive planning: methodological and conceptual issues in policy analysis. Am J Public Health 1996;86:684-690.

28. Juengst ET. "Prevention" and the goals of genetic medicine. Human Gene Ther 1995;6:1595-1605.

29. McConkie-Rosell A, Spiridigliozzi GA, Sullivan JA, Dawson DV, Lachiewicz AM Longitudinal study of the carrier testing process for fragile X syndrome: perceptions and coping. Am J Med Gen 2001;98:37-45.

30. Andrews LB, Fullerton JE, Holtzman NA, Motulsky AG, editors. Assessing genetic risks: implications for health and social policy. Washington, DC: National Academy of Sciences, 1994

31. Holtzman NA, Watson MS, editors. Promoting safe and effective genetic testing in the United States: Final report of the task force on genetic testing. Bethesda, Maryland: National Institutes of Health, 1997.
32. Boyle P. Genetic services, social context, and public priorities. In: Aronowitz S, Martinson B, Menser M, editors. Technoscience and cyberculture. New York: Routledge, 1996:205-211.

33. Khoury MJ, McCabe LL, McCabe ERB. Population screening in the age of genomic medicine. N Engl J Med 2003;348:50-58.

34. McCabe LL, McCabe ERB. Newborn screening as a model for population screening. Mol Genet Metab 2002;75:299-307.

35. Therrell BL. U.S. newborn screening policy dilemmas for the twenty-first century. Mol Genet Metab 2001;74:64-74.

36. Kaufert PA. Health policy and the new genetics. Soc Sci Med 2000;51:821-829.

37. Patton MQ. Qualitative evaluation and research methods. Newbury Park: Sage Publications, 1990.

38. Skinner D, Rodriguez P, Bailey DB. Qualitative analysis of Latino parents' religious interpretations of their child's disability. J Early Interv 1999;22:271-285.

39. McConkie-Rosell A, Spiridigliozzi GA, Iafolla T, Tarleton J, Lachiewicz AM. Carrier testing in the fragile X syndrome: attitudes and opinions of obligate carriers. Am J Med Gen 1997;68:62-69.

40. Alper JS, Ard C, Asch A, Beckwith J, Conrad P, Geller LN, editors. The double-edged helix: social implications of genetics in a diverse society. Baltimore: The Johns Hopkins University Press, 2002.

41. Conrad P, Gabe J, editors. Sociological perspectives on the new genetics. Oxford: Blackwell, 1999.

42. Davis D. Genetic dilemmas: reproductive technology, parental choices, and children's futures. New York: Routledge, 2001.

43. Andrews LB. Future perfect: confronting decisions about genetics. New York: Columbia University Press, 2001.

44. Parens E, Asch A. The disability rights critique of genetic testing: Reflections and recommendations. Hastings Cent Rep 1999;29:S1-S22.

45. Asch A. Prenatal diagnosis and selective abortion: A challenge to practice and policy In: Alper JS, Ard C, Asch A, Beckwith J, Conrad P, Geller LN, editors. The doubleedged helix: social implications of genetics in a diverse society. Baltimore: The Johns Hopkins University Press, 2002:123-150.

46. Parens E, Asch A, editors. Prenatal testing and disability rights. Washington, DC: Georgetown University Press, 2000.

47. Nelkin D. The social dynamics of genetic testing: The case of Fragile-X. Med Anthro Q 1996;10:537-550.

48. Henderson G. Research in medical ethics: genetic diagnosis. In: Sugarman J, Sulmasy DP, editors. Methods in medical ethics. Washington, DC: Georgetown University Press, 2001:267-285.

49. Wertz DC, Fanos JH, Reilly PR. Genetic testing for children and adolescents: who decides? JAMA 1994;272:875-881.

50. Markens S. Invisible women: gender, genetics and reproduction. In: Alper JS, Ard C Asch A, Beckwith J, Conrad P, Geller LN, editors. The double-edged helix: Socia implications of genetics in a diverse society. Baltimore: The Johns Hopkins University Press, 2002:102-122.

51. Browner $\mathrm{CH}$, Press N. The normalization of prenatal diagnosis testing. In: Ginsburg $\mathrm{F}$, Rapp R, editors. The politics of reproduction: the global politics of reproduction. Berkeley: University of California Press, 1995:307-322.

52. Press N, Browner CH. Why women say yes to prenatal diagnosis. Soc Sci Med 1997; 45:979-989.

53. Rapp R. Testing women, testing the fetus: The social impact of amniocentesis in America. New York: Routledge, 1999.

54. Singer E, Corning A, Lamias M. The poll-trends: genetic testing, engineering, and therapy: Awareness and attitudes. Public Opinion Q 1998;62:633-664.

55. Lerman C, Croyle RT, Tercyak KP, Hamann H. Genetic testing: Psychological aspects and implications. J Consult Clin Psychol 2002;70:784-797. 